\title{
Role of endotoxin in the pathogenicity of Neisseria gonorrhoeae colonial types 1, 4 and 5 determined by chicken embryo model
}

\author{
S. HAFIZ*
}

\begin{abstract}
Department of Medical Microbiology, University of Sheffield Medical School, Beech Hill Road, Sheffield S10 2RX
\end{abstract}

\begin{abstract}
Summary. The pathogenicity of Neisseria gonorrhoeae is a subject of considerable interest. It is believed that $N$. gonorrhoeae of colonial type 1 are pathogenic while those of type 4 are not. This is based on experimentation in human volunteers. The object of this study was to determine the reasons for the differences of susceptibility of chicken embryos to $N$. gonorrhoeae strains of colonial types 1, 4, 5 and 1R (a type-1 revertant from a non-pathogenic type 4 strain originally tested in human volunteers). Colonial types $1,5,1 \mathrm{R}$ and 4 caused mortality rates of $80,70,85$ and $20 \%$ respectively. This variation in lethality appeared to depend upon the availability of free extra-cellular endotoxin and this was confirmed by chicken-embryo inoculation results and electronmicroscopy of normal and heated colonial types 1, 4 and 5. Similar results were obtained by inoculating purified endotoxins from these types into chicken embryos. The results of this study suggest that endotoxins play a major role in the pathogenicity of $N$. gonorrhoeae and that the variations in virulence of the colonial types depends on the stability of their cell walls.
\end{abstract}

\section{Introduction}

Colonial variation in Neisseria gonorrhoeae was reported by Kellogg et al. (1963), who described four colonial types and established a clear relationship between colonial morphology and virulence for human volunteers. It is now generally accepted that colony types 1 and 2 are virulent whereas types 3 and 4 are not. A fifth colonial type was reported by Jephcott and Reyn (1971), and Hafiz et al. (1978) suggested that it was a pathogenic type on the basis of its effect after intravenous inoculation into 10day-old chicken embryos (Finkelstein, 1964). The intravenous injection of pathogenic and non-pathogenic colonial types of gonococci into 10-day-old chicken embryos has produced results consistent with, and parallel to, those obtained by intraurethral inoculation in human volunteers (Bumgarner and Finkelstein, 1973; Diena et al. 1975) $N$. gonorrhoeae isolates from clinical specimens are of colonial types 1 and 2 , and they degrade to type 3 and 4 on subsequent subcultures. Hafiz et al. (1977)

Received 22 Jul. 1985; accepted 25 Sep. 1985.

* Present address: Department of Microbiology, The Aga Khan Hospital and Medical College, Stadium Road, P.O. Box 3500, Karachi, 5, Pakistan. showed that colonial type 4 could revert to type 1 in the presence of iron. Berry (1975) stated that the endotoxin is the only clearly established toxic component in gonococci as well as in other gramnegative bacteria such as meningococci and brucellae. Although the factors responsible for virulence of $N$. gonorrhoeae are still ill-understood, Berry went further and suggested that, by a process of elimination, it could be assumed that endotoxin is responsible for host damage. It is also interesting to note that Scholz in 1900 introduced killed gonococci into the human urethra which then became transiently inflamed (cited by McEntegart, 1975). This observation further implied the importance of gonococcal endotoxin as one of the possible agents responsible for host damage. Ovc̈innikov and Delektorskij (1971) reported that $N$. gonorrhoeae secreted endotoxin blebs.

In an attempt to show that changes observed in in-vitro colonial morphology of gonococci in reverting from type 4 to type 1 are associated with changes in virulence, the chicken-embryo model has been used for pathogenicity studies. The role of endotoxin in the pathogenicity of several colonial types has also been investigated. Experiments were performed with whole live cells, cells inactivated by heat or formalin, and with extracted endotoxin. 


\section{Materials and methods}

\section{Organisms}

$N$. gonorrhoeae strain F62, colonial types 1,4 and 5 were all derived from a single clinical isolate obtained from Dr D. S. Kellogg, C.D.C., Atlanta, GA, USA. Type $1 \mathrm{R}$ (a revertant type 1 derived from the type- 4 culture of F62) was also studied. The four colonial types were grown for $18-20 \mathrm{~h}$ at $36 \mathrm{C}$ on GC medium (Difco) with defined supplement (Kellogg et al., 1963) $2^{\circ}$ and the identity of the colonial types confirmed by plate microscopy with a combination of incident and transmitted light. For injection into the chicken embryos the growth on this medium of each type was suspended, separately, in phosphate-buffered saline, $\mathrm{pH} 7 \cdot 2$ (PBS), and the suspensions were diluted to give an inoculum of $c .10^{6} \mathrm{cfu} / \mathrm{ml}$ as assessed by nephelometry (EEL Nephelometer). The nephelometer had been standardised by comparison of a series of readings with total viable counts (Miles et al., 1938) of gonococcal suspensions.

\section{Heat treatment of $N$. gonorrhoeae}

A suspension of $10^{6} \mathrm{cfu} / \mathrm{ml}$ in PBS of each type was heated at $60 \mathrm{C}$ for $30 \mathrm{~min}$; subsequent subcultures were sterile.

\section{Formol-saline treatment}

Cells of each type were harvested in PBS and centrifuged at $600 \mathrm{~g}$ for $30 \mathrm{~min}$, and the deposit was treated with $10 \%$ formol-saline (formaldehyde $10 \%$ in saline) overnight. The killed cells were washed three times in PBS and resuspended in PBS to give a concentration equivalent to c. $10^{6} \mathrm{cfu} / \mathrm{ml}$ as assessed by nephelometry.

\section{Preparation of endotoxin}

Endotoxin was extracted from all four colonial types of gonococci. Each colonial type was grown on GC medium and harvested into a universal container (c. $1 \mathrm{~g}$ wet weight) and $20 \mathrm{ml}$ of $45 \%$ aqueous phenol was added (Maeland, 1968). The gonococcal suspensions in aqueous phenol were incubated at $37^{\circ} \mathrm{C}$ for $30 \mathrm{~min}$ and then centrifuged at $3000 \mathrm{~g}$ for $45 \mathrm{~min}$. After centrifugation three layers were distinct. The contents of the centrifuged containers were allowed to stand at $4 \mathrm{C}$ for $20-24 \mathrm{~h}$. The clear top aqueous layer. containing free endotoxin only. was removed gently with a Pasteur pipette into a clean, sterile universal container. To ensure complete removal of volatile phenol, the endotoxin preparation was heated in an open container in a hot-water bath at $55 \mathrm{C}$ for $1 \mathrm{~h}$ and then the product was treated with $4 \mathrm{mg}$ of ribonuclease $A$ (Koch Light Laboratories Ltd) and incubated at $37^{\circ} \mathrm{C}$ for $18 \mathrm{~h}$ (Perry et al. 1975). The endotoxin extract, in approximately $20-\mathrm{ml}$ volumes, was dialysed against cold running tap water for about $48 \mathrm{~h}$ in Visking ${ }^{\otimes}$ cellophane tubing with an inflated diameter of $6.3 \mathrm{~mm}$ (Scientific Instruments Centre Ltd) and finally lyophilised in a high- vacuum freeze drier (Model EF03, Edwards, Manor Royal, Crawley, Sussex). The resultant white powder of purified endotoxin was weighed and then dissolved in PBS to give a final concentration of $0.1 \mathrm{mg} / \mathrm{ml}$ for each preparation.

\section{Lethality test}

Series 1 . Embryonated eggs, 10 days old, were obtained from a local farm. While candling, rectangular markings approximately $4 \mathrm{~mm} \times 6 \mathrm{~mm}$ were made over a prominent allantoic vein. The egg shell was cut with a dental drill along the markings and the shell flap was lifted off with an 18 gauge needle without damaging the chorio-allantoic membrane. The eggs were placed in a humidified incubator at $37^{\circ} \mathrm{C}$ for $2 \mathrm{~h}$ to allow fixation of the veins before inoculation and to allow the embryos to settle, thus helping to prevent any haemorrhage. Whilst monitoring by transillumination, the chicken embryos were given intravenous injections of $0.1 \mathrm{ml}$ of the appropriate suspension (i.e., $10^{5} \mathrm{cfu}$ or equivalent of live or killed $N$. gonorrhoeae or $10 \mu \mathrm{g}$ of purified endotoxin) with a 27 gauge needle; control eggs received $0.1 \mathrm{ml}$ of PBS. After inoculation the eggs were returned to the incubator at $36 \mathrm{C}$ and candled daily for 3 days. Suspected deaths were confirmed by opening the eggs. Dead embryos were fixed in formol saline and thin sections of the brain and the visceral organs were cut and stained by Haematoxylin and Eosin and by Gram's staining methods.

Series 2. In further experiments, $N$. gonorrhoeae of the four colonial types were injected into a total of 48 embryos. Two eggs were opened at hourly intervals and the dead embryos were cut into two. One half was fixed and embedded; thin sections were cut and examined histologically for pathological changes. The other halves of the chicken embryos were chopped, emulsified in PBS and $0.1 \mathrm{ml}$ spread on plates of GC medium for recovery of viable gonococci.

\section{Electronmicroscopy}

The various cell suspensions were examined by electronmicroscopy. Cells were harvested by centrifugation at $1000 \mathrm{rpm}(150 \mathrm{~g})$ for $5 \mathrm{~min}$ to form a pellet, washed three times with PBS, fixed with glutaraldehyde $3 \%$ in cacodylate buffer, and then post fixed with $1 \%$ aqueous osmium tetroxide. The material was dehydrated with increasing concentrations of ethyl alcohol and then embedded in low viscosity epoxy resin (Spurr, 1969). Ultrathin sections were cut on a Reichert Ultra-microtome and stained with uranyl acetate and lead citrate. The sections were examined with a AEI EM6B electronmicroscope at magnifications up to 50000 .

\section{Results}

Effects of whole live cells on chicken embryos

The deaths of the chicken embryos after inocula- 
Table. The effect of intravenous inoculation of $N$. gonorrhoeae preparations into chicken embryos

\begin{tabular}{|c|c|c|c|c|c|c|}
\hline \multirow[b]{2}{*}{ Colonial type } & \multirow[b]{2}{*}{ Cell preparations } & \multirow{2}{*}{$\begin{array}{l}\text { Number of } \\
\text { chicken } \\
\text { embryos used }\end{array}$} & \multicolumn{3}{|c|}{$\begin{array}{c}\text { Number of deaths } \\
\text { of chicken } \\
\text { embryos after }\end{array}$} & \multirow{2}{*}{$\begin{array}{l}\text { Percentage } \\
\text { mortality } \\
\text { after } 72 \mathrm{~h}\end{array}$} \\
\hline & & & $24 \mathrm{~h}$ & $48 \mathrm{~h}$ & $72 \mathrm{~h}$ & \\
\hline \multirow{4}{*}{1} & Live cells & 30 & 24 & 24 & 24 & 80 \\
\hline & Heated & 20 & 16 & 16 & 16 & 80 \\
\hline & Formalised & 20 & 2 & 6 & 6 & 30 \\
\hline & Freeze-dried Endotoxin & 30 & 21 & 21 & 21 & 70 \\
\hline \multirow{4}{*}{4} & Live cells & 30 & 7 & 7 & 7 & 23 \\
\hline & Heated & 20 & 16 & 16 & 16 & 80 \\
\hline & Formalised & 20 & 1 & 4 & 4 & 20 \\
\hline & Freeze-dried Endotoxin & 20 & 14 & 14 & 14 & 70 \\
\hline \multirow{4}{*}{5} & Live cells & 30 & 6 & 9 & 21 & 70 \\
\hline & Heated & 20 & 16 & 16 & 16 & 80 \\
\hline & Formalised & 20 & 2 & 5 & 5 & 25 \\
\hline & Freeze-dried Endotoxin & 20 & 14 & 14 & 14 & 70 \\
\hline \multirow{2}{*}{$\begin{array}{l}\text { Reverted } \\
\text { type } 1 \text { (1R) }\end{array}$} & Live cells & 20 & 17 & 17 & 17 & 85 \\
\hline & PBS (negative control) & 30 & 0 & 0 & 0 & 0 \\
\hline
\end{tabular}

tion of various preparations of $N$. gonorrhoeae (Series 1) are shown in the table. Most deaths occurred between 18 and $24 \mathrm{~h}$. The percentage mortality up to $72 \mathrm{~h}$ with whole live cells of colonial types $1,4,5$ and $1 \mathrm{R}$ of gonococci varied from $85 \%$ (reverted type 1) to $23.33 \%$ (type 4 ). In series 2 , no organisms were recovered after $6 \mathrm{~h}$ or on the deaths of the embryos, although in the first $5 \mathrm{~h}$ viable organisms were recovered from the embryos killed at hourly intervals.

Effect of heat- and formalin-treated cells or endotoxin of gonococcal types 1,4 , and 5

When cells of three colonial types (1, 4 and 5) were heated at $60^{\circ} \mathrm{C}$ and injected into chicken embryos (20 were given each preparation) the mortality rate was $80 \%$ with all three types. The same suspensions, treated with formalin but without heating, produced reduced mortality rates of $20-30 \%$ in sets of 20 embryos. There were no deaths in chicken embryos that had received PBS as negative controls. The mortality after injection of $10 \mu \mathrm{g}$ of freeze-dried purified endotoxin of colonial types 1,4 or 5 was $70 \%$ with each.

\section{Histopathological findings in dead embryos}

The typical gross pathological picture in chicken embryos was that of haemorrhagic lesions. The first minimal haemorrhagic signs appeared in the brains of chicken embryos after $10 \mathrm{~h}$ and by $21 \mathrm{~h}$ there were gross haemorrhagic lesions and engorgement of sinusoids. Deaths of embryos given purified endotoxin occurred within $24 \mathrm{~h}$. The embryos showed the same typical pathological changes seen in the embryos given live or killed $N$. gonorrhoeae; signs of these changes were first noticeable $6 \mathrm{~h}$ after inoculation.

\section{Electronmicroscopy}

The electronmicroscopic appearance of heated and unheated cells of $N$. gonorrhoeae colonial types 1,4 and 5 are shown in figs. 1-6. Endotoxin blebs were seen on cells of unheated virulent colonial type 1 (fig. 1); by contrast the unheated avirulent colonial type 4 had a more stable outer cell wall with no distinct endotoxin blebs evident (fig. 3). There were no differences between the appearances of the heatkilled gonococci of colonial types 1, 4 and 5 (figs. 2, 4 and 6); with each type the outer cell walls were partially disrupted and there were endotoxin blebs lying free from the cells.

\section{Discussion}

This study confirmed that the gonococci of 
colonial types 1 and 5 were virulent for the chicken embryos whereas gonococci of colonial type 4 were relatively avirulent (Bumgarner and Finkelstein 1973; Diena et al., 1975; Hafiz et al., 1978). The morphological change from colonial type 4 to colonial type I in vitro (Hafiz et al., 1977) was shown to be a true reversion because the virulence of the reverted colonial type 1 for chicken embryos was increased to at least the same as that of the original type- 1 culture.

The failure to recover viable gonococci from the cultured specimens of the dead chicken embryos $6 \mathrm{~h}$ after inoculation, and the histological findings of severe haemorrhage and engorgement of sinusoids in dead embryos suggest that death of the chicken embryos was due to endotoxin. This was further supported by the findings that the pathogenicity of heat-killed colonial types 1 and 5 was preserved while formalin-fixation considerably reduced pathogenicity. This suggests that heating liberates endotoxin whereas formalin treatment preserves the cell wall, thus reducing the liberation of endotoxin. The increased virulence of heat-killed colonial type 4 cells was surprising. This interesting finding could mean that heating altered the cell-wall stability of colonial type 4 gonococci in such a way
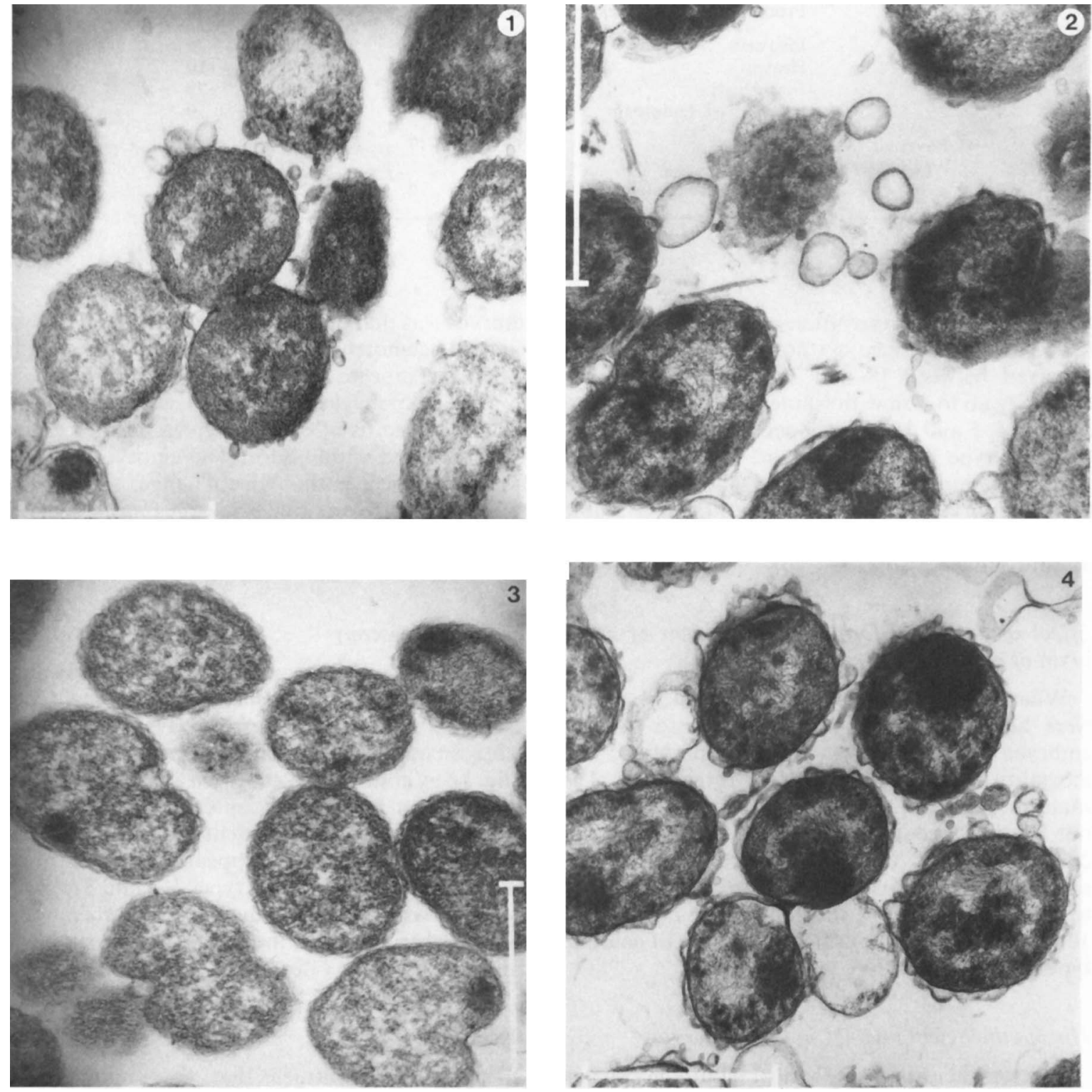

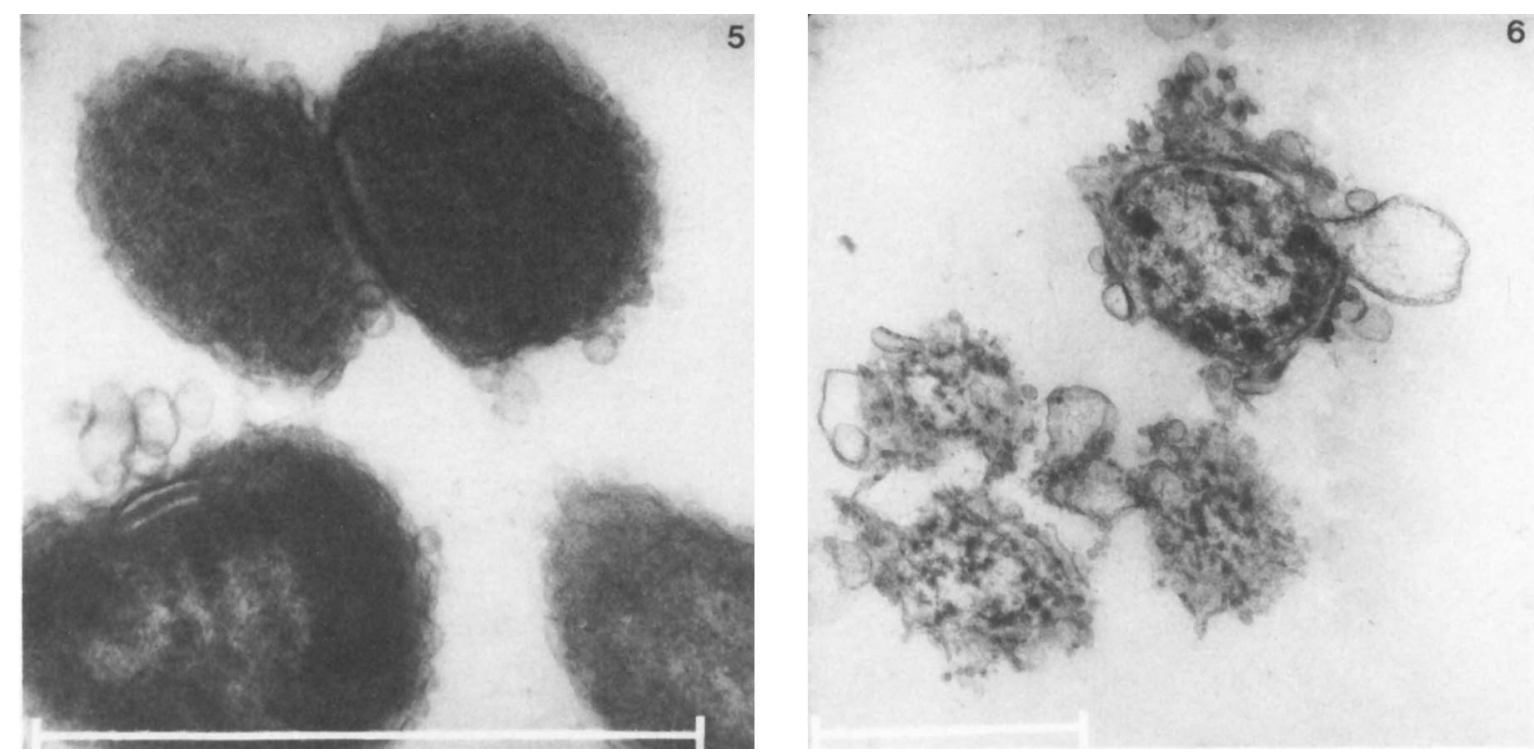

Figs. 1-6. Electronmicrographs of $N$. gonorrhoeae colonial types 1,4 and 5 before and after heating: 1 , unheated type $1 ; 2$, heated type $1 ; 3$, unheated type: $4 ; 4$, heated type 4 ; 5 , unheated type 5 ; and 6 , heated type 5 . Bar $=1 \mu \mathrm{m}$.

as to release endotoxin more easily and make it available to cause the same effect on chicken embryos as was found with the unheated and heated cells of the virulent types. Electronmicroscopic examination of heated and unheated cells of the three colonial types of gonococci revealed that unheated cells of virulent colonial types 1 and 5 carry small blebs of endotoxin which confirmed the findings of Grimble and Armitage (1974). The heated cells of all three colonial types released

\section{REFERENCES}

Berry L J 1975 Metabolic effects of endotoxin. In: Schlessinger D (ed) Microbiology 1975. American Society for Microbiology, Washington D.C., pp. 315.

Bumgarner L R, Finkelstein R A 1973 Pathogenesis and immunology of experimental gonococcal infection: virulence of colony types of Neisseria gonorrhoeae for chicken embryos. Infection and Immunity, 8:919-924.

Diena B B, Lavergne G, Reyn A, Ashton F E, Wallace R, Perry M, Daoust V 1975 The chick embryo in studies of virulence and immunity with Neisseria gonorrhoeae. Revue Canadienne de Biologie, 34:213-220.

Finkelstein R A 1964 Observations on mode of action of endotoxin in chick embryo. Proceedings of the Society of Experimental Biology and Medicine 115:702-707.

Grimble A, Armitage L R G 1974 Surface structures of the gonococcus. British Journal of Venereal Diseases 50:354 359.

Hafiz S, McEntegart M G, Jephcott A E 1977 Reversion of Kellogg's colonial types of Neisseria gonorrhoeae in liquid medium. Journal of Medical Microbiology 10:377-380.

Hafiz S, Jennings R, McEntegart M G, Jephcott A E $1978 \mathrm{~N}$. gonorrhoeae: pathogenicity of colonial type 5. Journal of Clinical Pathology 31:437-438. endotoxin. Inoculation of purified endotoxin extracted from the four colonial types had the same effect; all were equally potent. Chicken embryo lethality tests suggest that the pathogenicity of $N$. gonorrhoeae colonial types is related to the presence of free endotoxin, which may thus play an important role in the pathogenicity of $N$. gonorrhoeae.

The help and guidance received from Professor B. I. Duerden in drafting this manuscript is acknowledged.

Jephcott A E, Reyn A 1971 Neisseria gonorrhoeae. Colony variation I. Acta Pathologica et Microbiologica Scandinavica, Section B 79:609-614.

Kellogg D S, Peacock W L, Deacon W E, Brown L, Pirkle C I 1963 Neisseria gonorrhoeae. I. Virulence genetically linked to clonal variation. Journal of Bacteriology 85:1274-1279.

Maeland J A 1968 Antigenic properties of various preparations of Neisseria gonorrhoeae endotoxin. Acta Pathologica et Microbiologica Scandinavica 73:413-422.

McEntegart M G 1975 Fundamental research developments. In: Morton R S, Harris J R W (eds) Recent advances in sexually transmitted diseases. 1 Churchill Livingstone, Edinburgh, $\mathrm{p}$ 59.

Miles A A, Misra S S, Irwin J O 1938 The estimation of the bacterial power of blood. Journal of Hygiene 38:732-749.

Ovëinnikov N M, Delektorskij V V 1971 Electron microscope studies of gonococci in the urethral sections of patients with gonorrhoea. British Journal of Venereal Diseases 47:419439.

Perry M B, Daoust V, Diena B. B, Ashton F E, Wallace R 1975 The lipopolysaccharides of Neisseria gonorrhoeae colony types 1 and 4. Canadian Journal of Biochemistry 53:623-629.

Spurr A R 1969 A low-viscosity epoxy resin embedding medium for electron microscopy. Journal of Ultrastructure Research, 26:31-43. 